\title{
Application of dried blood spots combined with high-performance liquid chromatography coupled with electrospray ionisation tandem mass spectrometry for simultaneous quantification of vincristine and actinomycin-D
}

\author{
Carola W. N. Damen • Hilde Rosing • \\ Jan H. M. Schellens • Jos H. Beijnen
}

Received: 13 February 2009/Revised: 26 March 2009/Accepted: 26 March 2009/Published online: 24 April 2009

(C) The Author(s) 2009. This article is published with open access at Springerlink.com

\begin{abstract}
A sensitive, specific and efficient high-performance liquid chromatography-tandem mass spectrometry assay for the simultaneous determination of vincristine and actinomycin-D in human dried blood spots is presented. Dried blood spots were punched out of a collection paper with a 0.25 in.-diameter punch. The analytes were extracted from the punched-out disc using sonication during $15 \mathrm{~min}$ in a mixture of acetonitrile-methanol-water $(1: 1: 1, v / v / v)$ containing the internal standard vinorelbine. Twenty-microlitre volumes were injected onto the HPLC system. Separation was achieved on a $50 \times 2.1 \mathrm{~mm}$ ID Xbridge $\mathrm{C}_{18}$ column using elution with $1 \mathrm{mM}$ ammonium acetate-acetonitrile (70:30, $v / v)$ adjusted to $\mathrm{pH} 10.5$ with ammonia and run in a gradient with methanol at a flow rate of $0.4 \mathrm{~mL} / \mathrm{min}$. HPLC run time was $6 \mathrm{~min}$. The assay quantifies vincristine from 1 to $100 \mathrm{ng} / \mathrm{mL}$ and actinomycine-D from 2 to $250 \mathrm{ng} / \mathrm{mL}$ using a blood sample obtained by a simple finger prick. Validation
\end{abstract}

C. W. N. Damen $(\bowtie) \cdot H$. Rosing $\cdot$ J. H. Beijnen

Department of Pharmacy \& Pharmacology,

Slotervaart Hospital/The Netherlands Cancer Institute,

Louwesweg 6,

1066 EC Amsterdam, The Netherlands

e-mail: carola.damen@slz.nl

J. H. M. Schellens · J. H. Beijnen

Science Faculty, Department of Pharmaceutical Sciences,

Division of Biomedical Analysis, Utrecht University,

P.O. Box 80082, 3508 TB Utrecht, The Netherlands

\section{J. H. M. Schellens}

Department of Medical Oncology,

The Netherlands Cancer Institute,

Plesmanlaan 121,

1066 CX Amsterdam, The Netherlands results demonstrate that vincristine and actinomycin-D can be accurately and precisely quantified in human dried blood spots with the presented method. The assay can now be used to support clinical pharmacologic studies with vincristine and actinomycin-D.

Keywords Dried blood spot · Filter paper - Collection cards . Vincristine $\cdot$ Actinomycin-D $\cdot$ Liquid chromatography $\cdot$ Mass spectrometry $\cdot$ Electrospray ionisation $\cdot$ ESI-LS-MS/MS

\section{Introduction}

Traditionally, pharmacokinetic studies are performed using plasma obtained by venous sampling in the clinic. Recently, many reports have become available describing the use of dried blood spots for sampling and quantification of drugs. In these reports, dried blood spots are used for the therapeutic drug monitoring (TDM) of e.g. benzodiazepines [1], anti-malarial agents [2-9], anti-epileptics [10, 11], immunosuppressants [12-16], antibiotics [17-19], bacteriostatics [20], analgesics [21-24], bronchodilators [25] and antiretroviral drugs [26, 27]. Dried blood spot samples are obtained from a finger prick with an automatic lancet. For TDM, sampling blood on specimen collection cards has many advantages. The sample collection is much easier than performing a venipuncture, and patients can even obtain the samples themselves at home.

In our department, we previously developed a highperformance liquid chromatography coupled with tandem mass spectrometry (HPLC-MS/MS) method for the simultaneous quantification of vincristine and actinomycin-D in 
plasma [28]. This method was used to support pharmacokinetic studies in children with a Wilms' tumour in Malawi. Frequent venipuncture in these children is difficult, the setting is resource-limited, and all samples have to be shipped to our department in the Netherlands for analysis.

In this study, we have tested whether dried blood spots can be used for the simultaneous quantification of vincristine and actinomycin-D for use in pharmacokinetic studies. Not only the sampling procedure has been simplified, also the dried blood spots can be easily stored and transported [29]. The method is fully validated according to the Food and Drug Administration (FDA) guidelines on bioanalytical method validation [30, 31]. The assay can now be successfully applied in clinical pharmacological studies with vincristine and actinomycin-D, for example in malnourished children with a Wilms' tumour in Malawi.

\section{Experimental}

Chemicals and materials

Vincristine sulphate $\left(\mathrm{C}_{46} \mathrm{H}_{56} \mathrm{~N}_{4} \mathrm{O}_{10} * \mathrm{H}_{2} \mathrm{SO}_{4}\right)$ was purchased from Sequoia Research Products (Pangbourne, UK). Actinomycin-D $\left(\mathrm{C}_{62} \mathrm{H}_{86} \mathrm{~N}_{12} \mathrm{O}_{16}\right)$ and vinorelbine ditartrate $\left(\mathrm{C}_{45} \mathrm{H}_{54} \mathrm{~N}_{4} \mathrm{O}_{8} * 2 \mathrm{C}_{4} \mathrm{H}_{6} \mathrm{O}_{6}\right)$ were from Sigma-Aldrich Chemie (Steinheim, Germany). HPLC-grade methanol and acetonitrile originated from Biosolve Ltd. (Amsterdam, The Netherlands). Ammonium acetate and ammonia 25\% were from Merck (Darmstadt, Germany). Double-distilled water was used throughout analysis. Drug-free human blood with ethylenediamine tetraacetic acid (EDTA) as anticoagulant was obtained from healthy volunteers. Whatman 903 protein saver cards ${ }^{\circledR}$ for sample collection, $2 \mathrm{~mL}$ Eppendorf reaction vials, $1.5 \mathrm{~mL}$ autosampler vials and autosampler vials inserts were obtained from VWR international (Amsterdam, the Netherlands). A 0.25-in.-diameter punch was obtained from Fiskars (Madison, WI, USA).

Mass spectrometric and chromatographic conditions

The method was based on a previously developed assay, describing the simultaneous analysis of vincristine and actinomycin-D in plasma [28]. In brief, a Finnigan TSQ Quantum Ultra triple quadrupole mass spectrometer equipped with an electrospray ionisation (ESI) source (Thermo Fisher Scientific, Waltham, MA, USA) operating in the positive ion mode was used as a detector. For quantification, multiple reaction monitoring (MRM) chromatograms were acquired with LCquan ${ }^{\mathrm{TM}}$ software version 2.5 (Thermo Fisher Scientific). Positive ions were created at atmospheric pressure, and the quadrupoles were operating at unit resolution $(0.7 \mathrm{Da})$. Mass transitions of $m / z 825 \rightarrow 765$ for vincristine, $\mathrm{m} / \mathrm{z} 779 \rightarrow 122$ for vinorelbine and $\mathrm{m} / \mathrm{z} 1256 \rightarrow$ 857 for actinomycin-D were optimised. The ESI-MS/MS operating parameters used in this study are listed in Table 1.

Chromatographic separation of vincristine, actinomycin-D and the internal standard was carried out using a LC-20 AD Prominence binary solvent delivery system with a column oven, DGU-20A 3 online degasser and a SiL-HTc controller (Shimadzu, Kyoto, Japan). Mobile phase A consisted of $1 \mathrm{mM}$ ammonium acetate-acetonitrile (70:30, v/v) adjusted to $\mathrm{pH} 10.5$ using $25 \%$ ammonia, and mobile phase B was methanol. Gradient elution was applied at a flow rate of $0.4 \mathrm{~mL} / \mathrm{min}$ through an Xbridge $\mathrm{C}_{18}$ column $(50 \times 2.1 \mathrm{~mm}$ ID, particle size $5 \mu \mathrm{m}$ (Waters, Milford, MA, USA)) protected with a $0.5 \mu \mathrm{m}$ filter (Upchurch Scientific, Oak Harbor, WA, USA) and thermostatted at $40^{\circ} \mathrm{C}$. After an
Table 1 Finnigan TSQ quantum ultra triple quadrupole mass spectrometer settings

\begin{tabular}{|c|c|c|c|c|}
\hline Parameter & Setting & Vincristine & Vinorelbine & Actinomycin-D \\
\hline Run duration & $6 \min$ & & & \\
\hline Ionspray voltage & $+4.5 \mathrm{kV}$ & & & \\
\hline Sheath gas $\left(\mathrm{N}_{2}\right)$ & 49 psi & & & \\
\hline Auxiliary gas $\left(\mathrm{N}_{2}\right)$ & 23 psi & & & \\
\hline Ion sweep gas $\left(\mathrm{N}_{2}\right)$ & 5 psi & & & \\
\hline Skimmer offset & $10 \mathrm{~V}$ & & & \\
\hline Capillary temperature & $400^{\circ} \mathrm{C}$ & & & \\
\hline Collision pressure (argon) & 1.5 mTorr & & & \\
\hline Chrom filter peak width & $10 \mathrm{~s}$ & & & \\
\hline Quad MS/MS bias & $2.1 \mathrm{~V}$ & & & \\
\hline Q1 mass & & $825 \mathrm{amu}$ & $779 \mathrm{amu}$ & $1,256 \mathrm{amu}$ \\
\hline Q3 mass & & $765 \mathrm{amu}$ & $122 \mathrm{amu}$ & 857 amu \\
\hline Dwell time & & $100 \mathrm{~ms}$ & $100 \mathrm{~ms}$ & $100 \mathrm{~ms}$ \\
\hline Collision energy & & $37 \mathrm{~V}$ & $35 \mathrm{~V}$ & $34 \mathrm{~V}$ \\
\hline Tube lens voltage & & $169 \mathrm{~V}$ & $151 \mathrm{~V}$ & $206 \mathrm{~V}$ \\
\hline
\end{tabular}


isocratic hold for $30 \mathrm{~s}$ with $30 \% \mathrm{~B}$, a linear gradient was started from $30 \%$ to $100 \% \mathrm{~B}$ in $2.5 \mathrm{~min}$. The eluent composition was kept at $100 \% \mathrm{~B}$ for an additional $30 \mathrm{~s}$ before returning to the initial conditions. The column was equilibrated for $2.5 \mathrm{~min}$ before the next injection, leading to a total run time of $6 \mathrm{~min}$. Sample injections of $20 \mu \mathrm{L}$ were carried out, and the autosampler temperature was set at $10^{\circ} \mathrm{C}$.

The first $2 \mathrm{~min}$, the eluent flow was directed to waste by using a divert valve, then the valve was switched, and the eluent flow was directed to the mass spectrometer for $2 \mathrm{~min}$. After this period, the eluent was directed to waste again.

\section{Preparation of stock and working solutions}

Two sets of stock solutions of both vincristine and actinomycin-D in methanol were prepared from two independent weighings at a target concentration of $1 \mathrm{mg} / \mathrm{mL}$ as free base. One stock solution was used to prepare calibration standards, the other to prepare quality control (QC) samples. The stock solutions were further diluted with control human blood with EDTA as anticoagulant to obtain separate working solutions. For the first working solution of $10,000 \mathrm{ng} / \mathrm{mL}$, a volumetric flask of $5 \mathrm{~mL}$ is used, and $50 \mu \mathrm{L}$ of stock solution is added. This working solution is further diluted to obtain working solution in a range of 10 to $10,000 \mathrm{ng} / \mathrm{mL}$ for both vincristine and actinomycin-D for preparation of calibration standards. For the preparation of QC samples, separate working solutions in a different batch of control human blood with EDTA as anticoagulant were prepared in a concentration range of 10 to $10,000 \mathrm{ng} / \mathrm{mL}$ for both vincristine and actinomycin-D.

A stock solution of vinorelbine was prepared in methanol at a concentration of $1 \mathrm{mg} / \mathrm{mL}$ as free base and diluted to create a working solution of vinorelbine at a concentration of $10,000 \mathrm{ng} / \mathrm{mL}$ in methanol. The extraction solution was prepared by diluting this $10,000 \mathrm{ng} / \mathrm{mL}$ working solution to a target concentration of $10 \mathrm{ng} / \mathrm{mL}$ vinorelbine in an acetonitrile-methanol-water $(1: 1: 1, v / v / v)$ mixture. The working solutions in blood were used immediately after preparation. The stock and working solutions in methanol and the extraction solution containing the internal standard were stored at $-20^{\circ} \mathrm{C}$ until use.

Preparation of calibration standards and QC samples in dried blood spots

Calibration standards were prepared freshly from the whole blood working solutions in human blood with EDTA as anticoagulant to contain both vincristine and actinomycin-D in a calibration range of 1 to $100 \mathrm{ng} / \mathrm{mL}$ for vincristine and of 2 to $250 \mathrm{ng} / \mathrm{mL}$ for actinomycin-D. Calibration standards were spotted on the Whatman 903 filter paper cards by transferring $40 \mu \mathrm{L}$ onto the card with a volumetric pipette.
Thereafter, the blood spots were left to dry overnight at ambient temperatures. Calibration standards were prepared freshly before each run and processed and analysed in duplicate. QC samples were spiked separately to a different batch of control blood with EDTA as anticoagulant to contain both vincristine and actinomycin-D at concentrations of 1,3 , $30,80,100$ and $500 \mathrm{ng} / \mathrm{mL}$ for vincristine and at concentrations of 2, 6, 75,200,250 and 1,250 ng/mL for actinomycin-D by diluting the working solutions. All QC samples were spotted on filter cards and left to dry overnight. They were stored in the dark at ambient temperatures and additionally for long term stability experiments at $40-45^{\circ} \mathrm{C}$.

Extraction procedure

A 0.25 -in.-diameter disc was punched out of the dried blood spot, ensuring that an area completely filled with blood was obtained. The disc was transferred to a $2-\mathrm{mL}$ Eppendorf tube, and $100 \mu \mathrm{L}$ of extraction solution (acetonitrile-methanol-water $(1: 1: 1, v / v / v))$ containing the internal standard vinorelbine $(10 \mathrm{ng} / \mathrm{mL})$ was added. Vincristine and actinomycin-D were extracted from the dried blood spots by sonication for $15 \mathrm{~min}$. The tubes were centrifuged for $2 \mathrm{~min}$ at $23,100 \times \mathrm{g}$. The clear extract was transferred to a glass autosampler vial with insert.

\section{Validation}

A full validation procedure in human dried blood spots was executed including linearity, accuracy, precision, dilution test, specificity, matrix effect, recovery, cross-analyte/ internal standard interference, carry-over, spot size and stability. The validation was performed according to the FDA guidelines [30, 31] on bioanalytical method validation and on the guidelines of the 3rd AAPS/FDA bioanalytical workshop [32].

\section{Linearity}

Eight non-zero calibration standards in whole blood were prepared freshly before each run, spotted in duplicate on filter paper and analysed in three independent runs. Calibration curves (area ratio with the internal standard versus nominal concentration) were fitted by least-squares linear regression using $1 /$ concentration $^{2}$ as weighting factor. To assess linearity, deviations of the nominal concentrations should be within $85-115 \%$. At the lower limit of quantification (LLQ) level, a deviation of $\pm 20 \%$ was permitted.

\section{Accuracy and precision}

Accuracy, intra- and inter-assay precision of the method were determined by assaying six replicates of each of the 
validation samples at the LLQ, low, medium and high levels and upper limit of quantification (ULQ) concentration range in three separate runs. Accuracy was measured as the percentage of the concentration found as calculated with the calibration standards. The intra- and inter-assay accuracy should be within $\pm 15 \%$, except for the LLQ where a deviation of $\pm 20 \%$ was allowed. The intra- and inter-assay precision (relative standard deviation) should not exceed $15 \%$, except for the LLQ, where $20 \%$ deviation was accepted.

\section{Dilution test}

To test if samples with concentrations higher than ULQ (>ULQ) can be diluted with acceptable accuracy and precision, a dilution test was executed. A dried blood spot itself cannot be diluted; thus, it was tested if the extract could be diluted with blank extract containing the internal standard (Cal0 sample). A validation sample >ULQ (500 ng/mL for vincristine and $1,250 \mathrm{ng} / \mathrm{mL}$ for actinomycin-D) was extracted, and the extract was diluted ten times with Cal0 extract and analysed. This test was performed in six-fold in one analytical run.

\section{Selectivity, specificity and matrix factor}

Dried blood spots from six different batches of blank human blood were prepared and processed. The matrix factor was assessed by the simultaneous post-column infusion of a solution containing all analytes and the internal standard at a concentration of $2.5 \mu \mathrm{g} / \mathrm{mL}$ into the detector during the chromatographic analysis of extracts of the six different batches of human dried blood spots and the subsequent analysis of a mixture of acetonitrile-methanol-water $(1: 1: 1$, $v / v / v)$. The matrix factor was determined by comparing the signal obtained from the injection of a dried blood spot extract with the signal obtained from the injection of acetonitrile-methanol-water $(1: 1: 1, v / v / v)$ at the retention time of the analyte. The variability in matrix factors, as measured by the coefficient of variation, should be less than $15 \%$ [32]. Moreover, analysis of the blank extracts of the six different batches without post-column infusion was performed to ensure that no interfering peaks with the same retention times as vincristine or actinomycin-D larger than $20 \%$ of the response of an LLQ standard were observed. Additionally, no interfering peaks with the same retention time as internal standard vinorelbine larger than $5 \%$ of the response of the internal standard should be observed.

\section{Recovery}

Recoveries were determined at two concentration levels (low and high) in triplicate. A dried blood spot containing
$20 \mu \mathrm{L}$ blood was not punched out but completely extracted in $100 \mu \mathrm{L}$ of extraction solution. The peak areas of these validation samples were compared with the peak areas of samples spiked with the same amounts of analytes in acetonitrile-methanol-water $(1: 1: 1, v / v / v)$. This comparison leads to the total recovery. To calculate the extraction recovery, the total recovery has to be corrected for the matrix factor.

\section{Cross-analyte interference}

To investigate whether there is cross interference between vincristine, actinomycin-D and the internal standard vinorelbine, an interference check was performed. Control drugfree human blood was spiked separately at ULQ level with vincristine and actinomycine-D and spotted on filter cards. These samples were processed without internal standard vinorelbine. Additionally, a dried blood spot of drug-free blood was processed with internal standard vinorelbine in the absence of vincristine and actinomycin-D. The experiment was performed in singlicate. The response of any interfering peak with the same retention times as vincristine or actinomycin-D should be less than $20 \%$ of the response of a LLQ standard. The response of any interfering peak with the same retention time as internal standard vinorelbine should be less than $5 \%$ of the response of the internal standard.

\section{Carry-over}

Carry-over was tested by injecting two processed blank matrix samples sequentially after injecting an ULQ sample. The response in the first blank matrix at the retention times of the analytes or internal standard should be less than $20 \%$ of the mean response of a LLQ sample for the analytes and less than $5 \%$ of the mean response for the internal standard.

\section{Dried blood spot volume}

The influence of the volume from which the dried blood spot was obtained on the accuracy and precision was investigated by spotting two different volumes (20 and $60 \mu \mathrm{L})$ on filter cards in triplicate. Discs (0.25 in.) were punched out and quantified on calibration curves obtained from spots with a size of $40 \mu \mathrm{L}$. Deviations of the nominal concentrations should be within $85-115 \%$.

\section{Stability}

Stability experiments were performed to evaluate stabilities of the analytes in dried blood spots and under different storage and processing conditions. Stability of all analytes 
in stock solutions has been investigated and reported [28]. The stability of the internal standard solution was determined during $6 \mathrm{~h}$ at ambient temperatures and during longterm storage at $-20^{\circ} \mathrm{C}$. The stability of the processed samples was determined at $2-8^{\circ} \mathrm{C}$. The re-injection reproducibility in the autosampler was determined after $72 \mathrm{~h}$. The stability of the analytes in dried blood spots was assessed in a stove at $40-45^{\circ} \mathrm{C}$ after 3 months and at ambient temperatures. The above described stability experiments were executed at two concentration levels (QC low and high) except for the re-injection reproducibility in the autosampler where the QC at medium concentration was additionally tested. All experiments were performed in triplicate. The analytes are considered stable in the biological matrix or extracts if $85-115 \%$ of the initial concentration is recovered. The internal standard is considered stable if $80-120 \%$ of the initial concentration is recovered.

\section{Results and discussion}

\section{LC-MS/MS method}

In the previously developed method [28] for the quantification of vincristine and actinomycin-D in plasma, the chromatography and mass spectrometry were investigated extensively. This method was used to quantify the analytes in dried blood spots. Figure $1 \mathrm{a}, \mathrm{b}$ show the MS/MS spectrum of vincristine and actinomycin-D, respectively, with their structural formulas and proposed fragmentation pattern. The most abundant product ion for vincristine is the non-specific loss of water $(\mathrm{m} / \mathrm{z} 807)$; therefore, the second most intense ion $(\mathrm{m} / \mathrm{z} 765)$ was optimised during multiple reaction monitoring. The most intense fragment for actinomycin-D $(\mathrm{m} / \mathrm{z}$ 857) corresponds to opening of the peptide ring system. When both rings are opened during fragmentation, the fragment at $\mathrm{m} / \mathrm{z} 459$ originates for actinomycin-D. For vinorelbine, the most abundant product ion $(\mathrm{m} / \mathrm{z} 121)$ corresponds to the fragmentation of the large ring with seven carbon atoms and one nitrogen atom. There is a lot of tension in this ring system, and this explains why this part of the molecule will fragment first. The product ions as shown in Table 1 were optimised using MRM.

Representative chromatograms of vincristine, actinomycin$\mathrm{D}$ and the internal standard vinorelbine are depicted in Fig. 2. Asymmetry factors of 1.2 for vincristine and 1.3 for actinomycin-D and vinorelbine were established at ULQ level. Signal to noise ratios $(\mathrm{S} / \mathrm{N})$ at the LLQ level were approximately 40 for both vincristine and actinomycin-D. The retention factors $(k)$ were approximately 6.4 for vincristine, 7.9 for actinomycin-D and 8.2 for vinorelbine.
Extraction

In our department, a method has been developed for the quantification of anti-retroviral drugs in dried blood spots [27]. For this application, a mixture of methanolacetonitrile- $-0.2 \mathrm{M}$ zinc sulphate in water $(1: 1: 2, v / v / v)$ was used as extraction solvent. Unfortunately, this solvent appeared to be unsuitable for our assay using a basic mobile phase since zinc will form a zinc hydroxide precipitate. Therefore, different extraction solvents were investigated. The challenge is to extract vincristine and actinomycin-D from the filter paper and to retain blood components on the paper. From acetonitrile, methanol, acetone and ammonium sulphate, it is known that they are effective for protein precipitation in plasma samples [33]. We tested many different mixtures of these solvents for their extraction capabilities for vincristine and actinomycin-D from dried blood spots. The highest signal to noise ratios were obtained using the final mixture of acetonitrile-methanolwater $(1: 1: 1, v / v / v)$.

Additionally, we investigated the influence of the sonication time on the signal to noise ratio of vincristine and actinomycin-D. No difference was observed in signal to noise ratios when comparing sonication times of $15,30,45$ and $60 \mathrm{~min}$. Therefore, the final extraction method was sonication of the dried blood spot during $15 \mathrm{~min}$ with $100 \mu \mathrm{L}$ acetonitrile-methanol-water $(1: 1: 1, v / v / v)$ containing the internal standard.

\section{Validation}

\section{Linearity}

The assay was linear over a concentration range of 1 to $100 \mathrm{ng} / \mathrm{mL}$ for vincristine and 2 to $250 \mathrm{ng} / \mathrm{mL}$ for actinomycin-D. The linear regression of peak area versus the concentration $1 / x^{2}$ (the reciprocal of the squared concentration) was weighted to obtain the lowest total bias and the most constant bias across the range.

Correlation coefficients $\left(r^{2}\right)$ of 0.991 or better were obtained for both vincristine and actinomycin-D. For vincristine at all concentration levels, the deviations of measured concentrations from nominal concentrations were between $-4.15 \%$ and $7.32 \%$ with coefficient of variation (CV) values of less than $13.8 \%$. For actinomycin-D at all concentration levels, the deviations of measured concentrations from nominal concentrations were between $-2.30 \%$ and $1.01 \%$ with CV values of less than $8.26 \%$.

\section{Accuracy and precision}

Inter-assay performance data for vincristine and actinomycin$\mathrm{D}$ in human dried blood spots are summarised in Table 2. For 
Fig. $1 \mathrm{MS} / \mathrm{MS}$ product ion scans of vincristine (a, precursor ion $m / z$ 825), actinomycin-D (b, precursor ion $m / z$ 1256) and the internal standard vinorelbine (c, precursor ion $\mathrm{m} / \mathrm{z}$ 779)

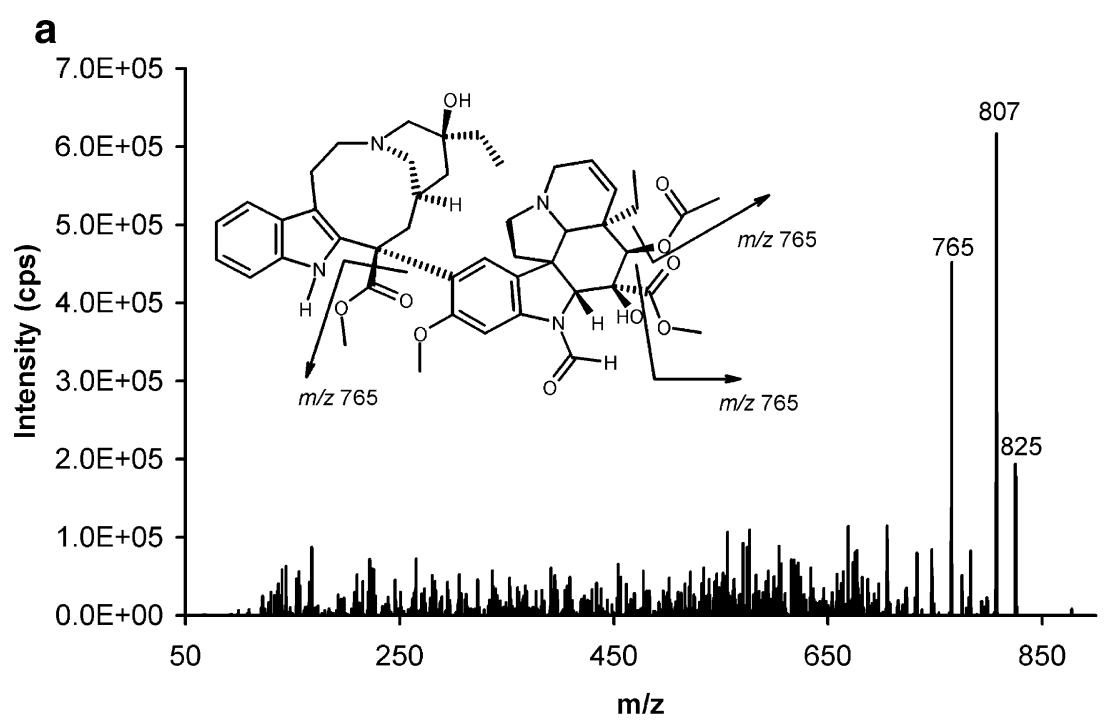

b
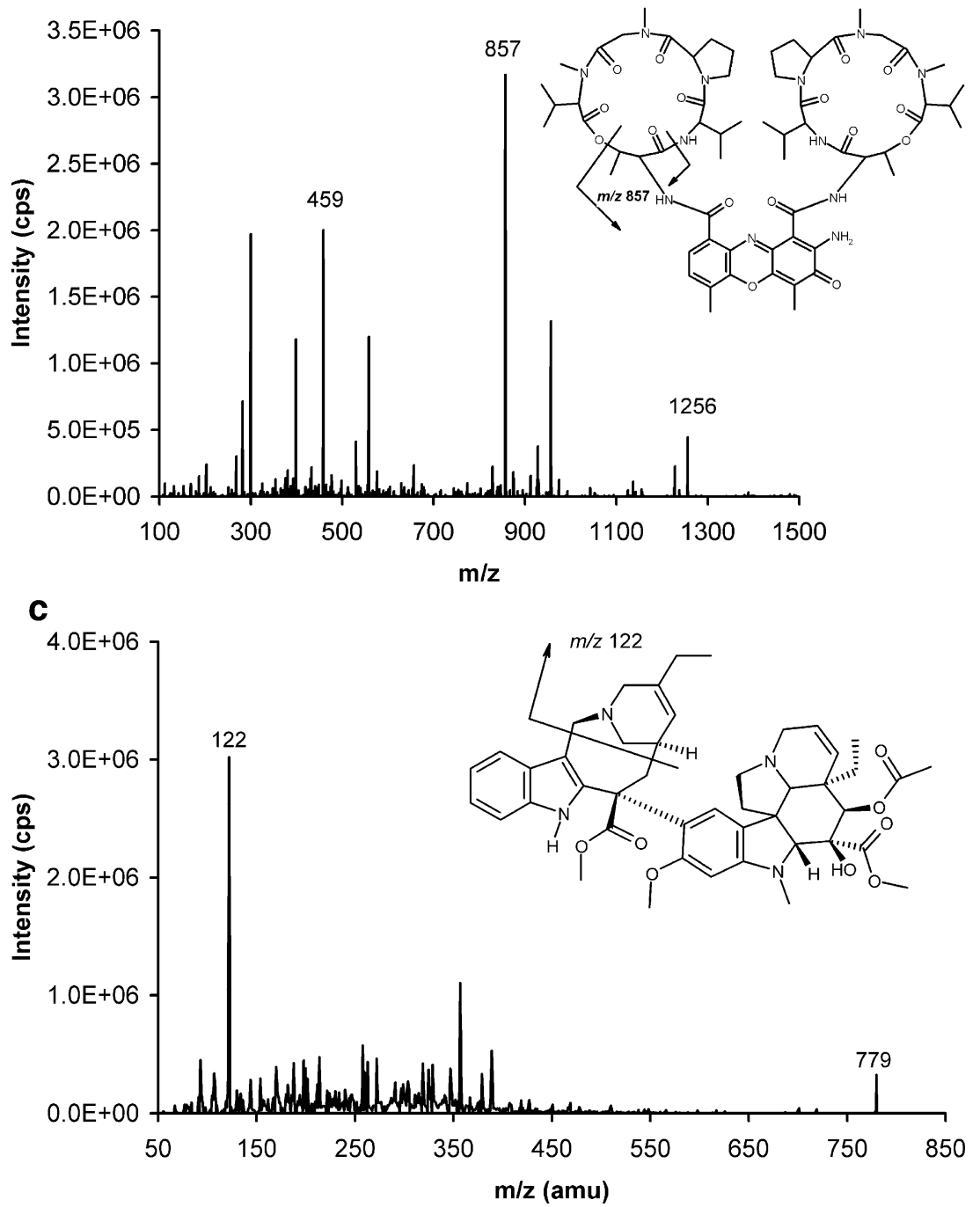
Fig. 2 Representative HPLCMS/MS chromatograms from a dried blood spot sample at the LLQ of vincristine (a, $1 \mathrm{ng} / \mathrm{mL})$, actinomycin-D (b, $2 \mathrm{ng} / \mathrm{mL})$ and the internal standard vinorelbine (c, $50 \mathrm{ng} / \mathrm{mL}$ )

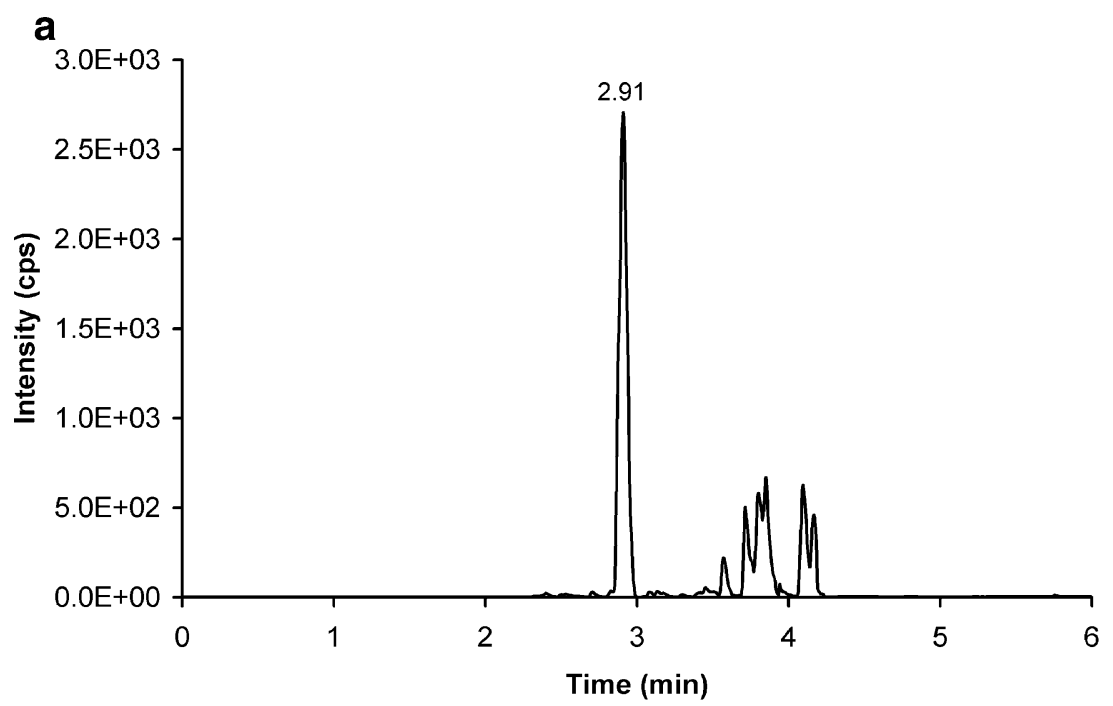

b

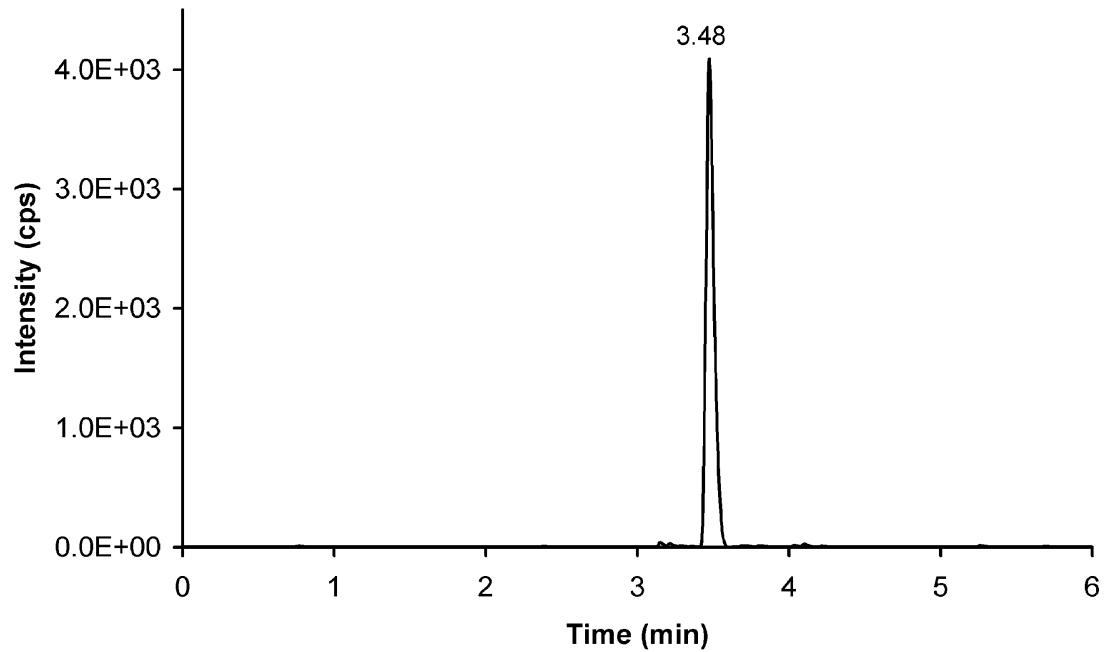

C

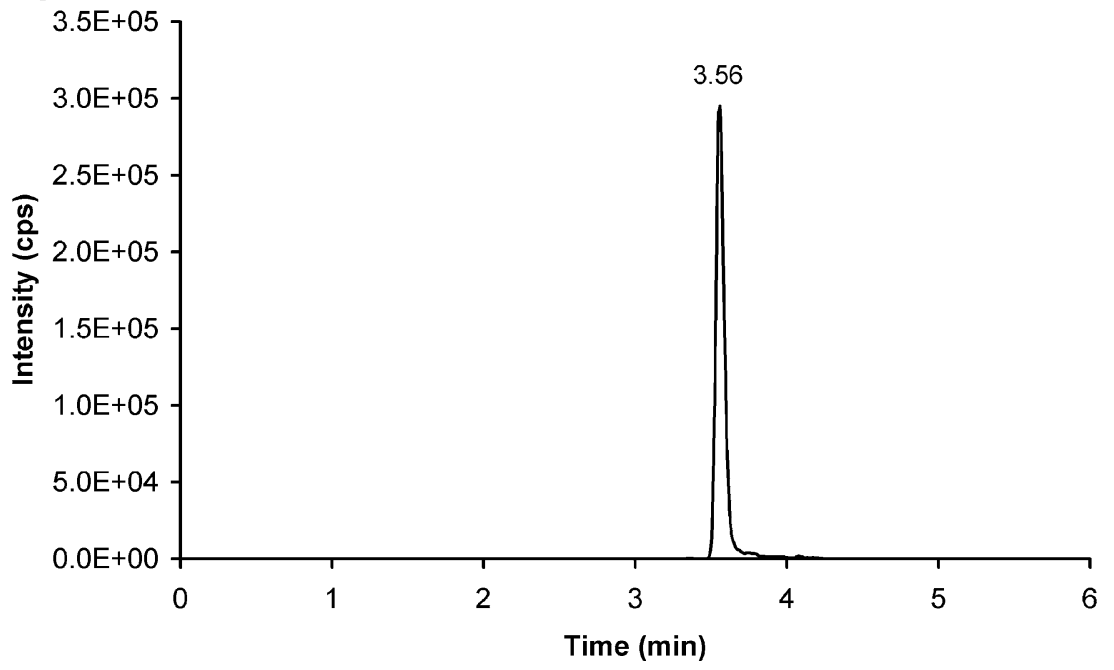


Table 2 Assay performance data for vincristine and actinomycin-D

\begin{tabular}{|c|c|c|c|c|c|}
\hline Compound & $\begin{array}{l}\text { Nominal conc. } \\
(\mathrm{ng} / \mathrm{mL})\end{array}$ & $\begin{array}{l}\text { Mean measured conc. } \\
\text { (ng/mL) }\end{array}$ & $\begin{array}{l}\text { Inter-assay bias } \\
(\%)\end{array}$ & $\begin{array}{l}\text { Inter-assay precision } \\
(\%)\end{array}$ & $\begin{array}{l}\text { No. of } \\
\text { replicates }\end{array}$ \\
\hline \multirow[t]{5}{*}{ Vincristine } & 1.00 & 1.03 & 2.93 & 15.4 & 18 \\
\hline & 3.00 & 3.09 & 2.83 & 9.45 & 18 \\
\hline & 30.0 & 30.8 & 2.67 & 12.1 & 18 \\
\hline & 80.0 & 86.4 & 8.00 & 9.74 & 18 \\
\hline & 100 & 102 & 2.06 & 11.3 & 18 \\
\hline \multirow[t]{5}{*}{ Actinomycin-D } & 2.03 & 2.32 & 14.1 & 12.0 & 18 \\
\hline & 6.08 & 5.83 & -4.07 & 11.0 & 18 \\
\hline & 76.0 & 76.4 & 0.504 & 8.79 & 18 \\
\hline & 203 & 204 & 0.657 & 10.5 & 18 \\
\hline & 253 & 233 & -8.06 & 6.85 & 18 \\
\hline
\end{tabular}

Conc. concentration

both vincristine and actinomycin-D, all intra- and inter-assay accuracies and precisions fulfilled the required criteria [30-32].

\section{Dilution test}

In a plasma assay, a sample above the ULQ can be diluted with control drug-free plasma before sample pretreatment. For dried blood spots, this procedure is not applicable. Therefore, it was investigated if sample above the ULQ can be diluted after the extraction. Extracts were diluted ten times with extraction solvent containing the internal standard. However, unacceptable accuracies and precisions were obtained. To keep the matrix factor constant, extracts of samples above the ULQ $(500 \mathrm{ng} / \mathrm{mL}$ vincristine and 1,250 ng/mL actinomycin-D) were diluted ten times with extracts of blank dried blood spots. This resulted in intra-assay accuracies of $89.2 \%$ and $106 \%$ for vincristine and actinomycin-D, respectively, and the intraassay precision was $5.49 \%$ for vincristine and $4.31 \%$ for actinomycin-D.

In conclusion, the validated range for vincristine and actinomycin-D when using vinorelbine as internal standard based on 0.25 inch diameter discs from dried blood spots is from 1 to $100 \mathrm{ng} / \mathrm{mL}$ for vincristine and from 2 to $250 \mathrm{ng} / \mathrm{mL}$ for actinomycin-D. When concentrations above the ULQ are expected, dried blood spots extracts can be diluted ten times with blank extract. Accuracies and precisions fulfilled the required criteria [30-32]

\section{Selectivity, specificity and matrix factor}

The matrix factor in blood spots prepared from six different batches of control drug-free blood with EDTA as anticoagulant was determined by injecting blank extracts with postcolumn infusion of the analytes in the mass spectrometer.
Figure 3 shows a typical overlay of the observed signals of a blank dried blood spot extract and acetonitrile-methanolwater $(1: 1: 1, v / v / v)$ in the mass transition of vincristine. Similar overlays were obtained for actinomycin-D and internal standard vinorelbine. The mean matrix factors and $\mathrm{CV}(n=6)$ for vincristine, actinomycin-D and vinorelbine were $1.54 \pm 6.14 \%, 0.564 \pm 7.37 \%$ and $0.736 \pm 12.8 \%$, respectively. Additionally, the blank matrix samples were injected without post-column infusion of the analytes. No co-eluting peaks $>20 \%$ of the vincristine and actinomycin$\mathrm{D}$ peak areas at LLQ level were observed and no co-eluting peaks $>5 \%$ of the area of the internal standard vinorelbine. Thus, the selectivity, specificity and matrix factor met the predefined criteria [32].

\section{Recovery}

The total recovery for the analytes and internal standard was determined. The total recovery of vincristine was $147 \%$ at QC low level and 157\% at QC high level. During the determination of the matrix factor, ion enhancement of $54 \%$ was observed; therefore, it can be concluded that the extraction recovery for vincristine is approximately $100 \%$. For actinomycin-D, the total recovery was $32.9 \%$ at QC low level and $36.7 \%$ at QC high level. With the determination of the matrix factor, ion suppression of $43.6 \%$ was observed, and therefore, it can be concluded that the extraction recovery of actinomycin-D is approximately $80 \%$. For the internal standard vinorelbine, ion suppression of $26.2 \%$ was observed. The total recovery was $63.9 \%$, and therefore, the extraction recovery was approximately $90 \%$.

Although the total recovery of actinomycin-D is low, due to severe ion suppression, a LLQ of $2 \mathrm{ng} / \mathrm{mL}$ can still be reached with acceptable accuracy and precision as shown in Table 2 . 
Fig. 3 Overlay of two typical chromatograms for the determination of the matrix factor by post-column infusion of analytes. The grey line shows the signal in the mass transition window of vincristine when a blank dried blood spot extract was injected; the black line shows the signal when acetonitrile-methanol-water $(1: 1: 1$, $v / v / v)$ was injected. The dashed line represents the response $(\mathrm{m} / \mathrm{z} 825$ to 765$)$ measure in time when vincristine is injected

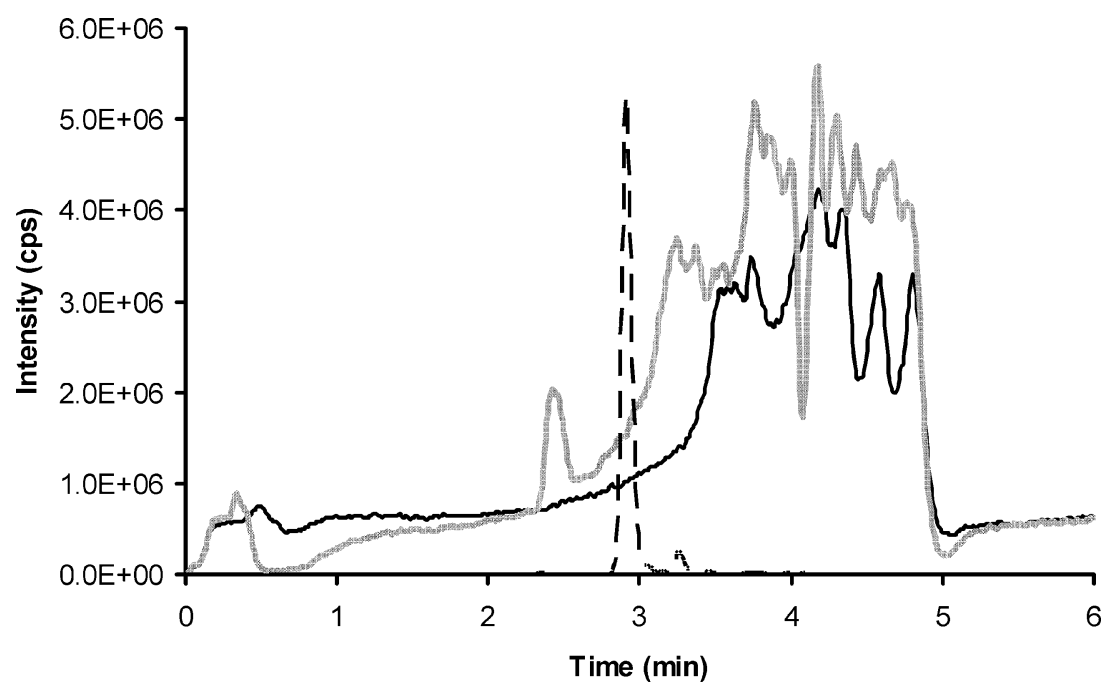

\section{Cross-analyte interference}

During the cross-analyte interference test, the interference at the retention times of vincristine and actinomycin-D was less than $20 \%$ of the response of their LLQ standards. Furthermore, no interfering peaks were detected with the same retention time as the internal standard vinorelbine. Thus, the cross-analyte/internal standard interference check met the predefined criteria.

\section{Carry-over}

No interfering peaks with peak areas $>20 \%$ of the peak areas at LLQ level for both vincristine and actinomycin-D were detected in processed blank dried blood spot samples injected after an ULQ sample. Additionally, no interfering peaks with peak areas $>5 \%$ of the peak area of internal standard vinorelbine were detected. Thus, the carry-over test met the predefined criteria.

\section{Dried blood spot volume}

The relationship between the volume of blood applied to the collection paper and the dried blood spot area obtained was previously investigated in our department [27]. A linear relationship was observed. For vincristine and actinomycin-D, it was investigated whether the blood volume and thus the spot size influenced accuracy and precision. As observed in Table 3, calculated accuracy and precision from 20 and $60 \mu \mathrm{L}$ blood spots at two concentration levels were all within $85-115 \%$ limits, indicating that the amount of blood spotted on the filter paper did not influence the amount of analyte present in the punched-out disc.

Table 3 Influence of spot volume on accuracy and precision for vincristine and actinomycin-D $(n=3)$

\begin{tabular}{|c|c|c|c|c|c|}
\hline Compound & $\begin{array}{l}\text { Amount of blood spotted } \\
\text { on paper }(\mu \mathrm{L})\end{array}$ & $\begin{array}{l}\text { Nominal conc. } \\
(\mathrm{ng} / \mathrm{mL})\end{array}$ & $\begin{array}{l}\text { Mean measured } \\
\text { concentration }(\mathrm{ng} / \mathrm{mL})\end{array}$ & $\begin{array}{l}\text { Intra-assay } \\
\text { accuracy }(\%)\end{array}$ & $\begin{array}{l}\text { Intra-assay } \\
\text { precision }(\%)\end{array}$ \\
\hline \multicolumn{6}{|l|}{ Vincristine } \\
\hline \multirow[t]{2}{*}{ Low } & 20 & 3.00 & 2.95 & -1.67 & 13.2 \\
\hline & 60 & 3.00 & 2.85 & -5.11 & 2.15 \\
\hline \multirow[t]{2}{*}{ High } & 20 & 80.0 & 79.1 & -1.12 & 5.21 \\
\hline & 60 & 80.0 & 77.8 & -2.71 & 6.35 \\
\hline \multicolumn{6}{|c|}{ Actinomycin-D } \\
\hline \multirow[t]{2}{*}{ Low } & 20 & 6.08 & 5.32 & -12.4 & 1.62 \\
\hline & 60 & 6.06 & 5.84 & -4.00 & 2.62 \\
\hline \multirow[t]{2}{*}{ High } & 20 & 203 & 208 & 2.46 & 3.15 \\
\hline & 60 & 203 & 222 & 9.36 & 1.62 \\
\hline
\end{tabular}


Table 4 Stability data for vincristine, actinomycin-D and internal standard vinorelbine $(n=3)$

\begin{tabular}{|c|c|c|c|c|c|}
\hline Matrix & Conditions & Initial conc. $(\mathrm{ng} / \mathrm{mL})$ & Found conc. (ng/mL) & Dev $(\%)$ & CV $(\%)$ \\
\hline \multicolumn{6}{|l|}{ Vincristine } \\
\hline \multirow[t]{2}{*}{ Dried blood spots } & \multirow[t]{2}{*}{ Ambient temperatures, 3 months } & 3.00 & 2.86 & -4.56 & 5.15 \\
\hline & & 79.8 & 71.2 & -10.8 & 5.13 \\
\hline \multirow[t]{2}{*}{ Dried blood spots } & \multirow[t]{2}{*}{$40-45^{\circ} \mathrm{C}, 3$ months } & 3.00 & 2.60 & -13.3 & 1.94 \\
\hline & & 79.8 & 69.4 & -13.1 & 1.70 \\
\hline \multirow[t]{2}{*}{ Final extract } & \multirow[t]{2}{*}{$2-8^{\circ} \mathrm{C}, 6$ days } & 3.06 & 3.00 & -1.96 & 2.14 \\
\hline & & 89.2 & 92.5 & 3.74 & 1.25 \\
\hline \multirow[t]{2}{*}{ Final extract } & \multirow[t]{2}{*}{ Autosampler, $10^{\circ} \mathrm{C}, 72 \mathrm{~h}$} & 3.06 & 3.24 & 5.77 & 2.14 \\
\hline & & 89.4 & 90.7 & 1.42 & 2.21 \\
\hline \multicolumn{6}{|l|}{ Actinomycin-D } \\
\hline \multirow[t]{2}{*}{ Dried blood spots } & \multirow[t]{2}{*}{ Ambient temperatures, 3 months } & 5.64 & 5.27 & -6.62 & 1.76 \\
\hline & & 207 & 197 & -4.82 & 2.88 \\
\hline \multirow[t]{2}{*}{ Dried blood spots } & \multirow[t]{2}{*}{$40-45^{\circ} \mathrm{C}, 3$ months } & 5.64 & 5.29 & -6.15 & 1.71 \\
\hline & & 207 & 180 & -13.0 & 2.74 \\
\hline \multirow[t]{2}{*}{ Final extract } & \multirow[t]{2}{*}{$2-8^{\circ} \mathrm{C}, 6$ days } & 5.79 & 6.06 & 4.72 & 7.75 \\
\hline & & 228 & 226 & -0.877 & 1.77 \\
\hline \multirow[t]{2}{*}{ Final extract } & \multirow[t]{2}{*}{ Autosampler, $10^{\circ} \mathrm{C}, 72 \mathrm{~h}$} & 5.79 & 6.12 & 5.76 & 3.34 \\
\hline & & 222 & 223 & 0.602 & 3.14 \\
\hline \multicolumn{6}{|l|}{ Vinorelbine } \\
\hline Extraction solvent (IS10) & Ambient, $6 \mathrm{~h}$ & 10.0 & 9.53 & -4.75 & 0.378 \\
\hline Extraction solvent (IS10) & $-20^{\circ} \mathrm{C}, 3$ months & 10.0 & 8.63 & -13.2 & 4.18 \\
\hline
\end{tabular}

Conc. concentration, Dev. deviation of initial concentration, $C V$ coefficient of variation

\section{Stability}

The stability data for vincristine and actinomycin-D are presented in Table 4. Vincristine and actinomycin-D were stable up to 6 days in the final dried blood spot extract at $2-$ $8^{\circ} \mathrm{C}$. Re-injection reproducibility was established, and the analytical run can be re-injected after at least $72 \mathrm{~h}$ of storage in the autosampler at $10^{\circ} \mathrm{C}$. Both vincristine and actinomycin-D are stable in human dried blood spots for at least 3 months at ambient temperatures and at $40-45^{\circ} \mathrm{C}$, making the application also suitable to support a study in Malawi, where we study pharmacokinetics in malnourished
Fig. 4 Concentration-time curve of vincristine obtained from dried blood spots after a bolus injection of $2 \mathrm{mg}$. Patient 1 (filled triangles was $70 \mathrm{~kg}$, and patient 2 (filled squares) was $96 \mathrm{~kg}$

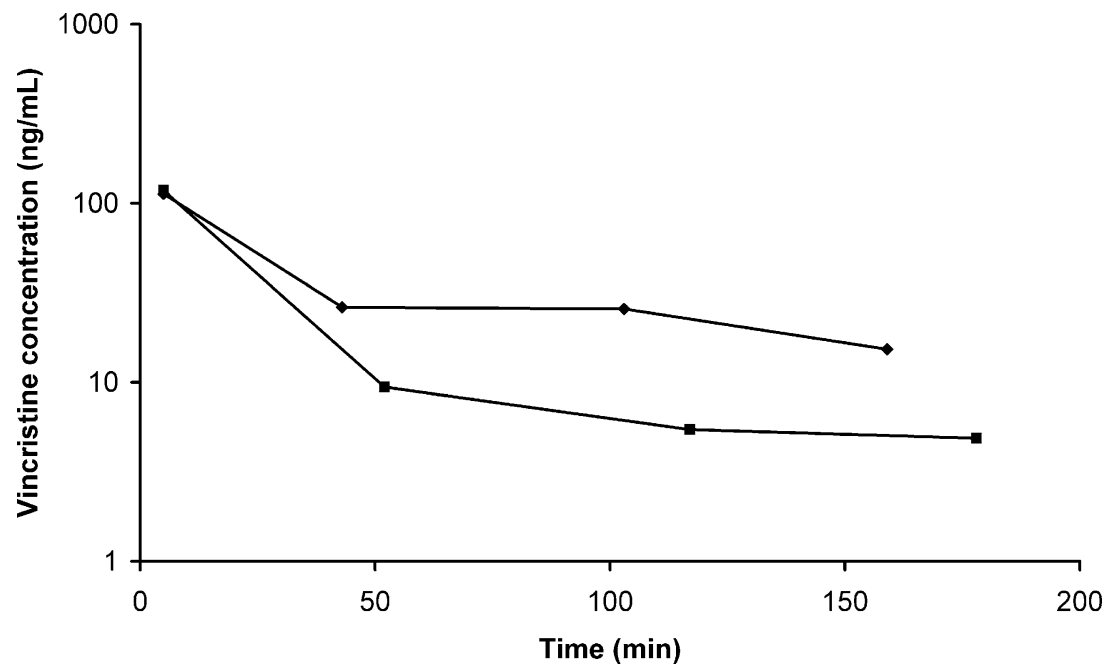


children with cancer. The extraction solvent containing the internal standard is stable for at least $6 \mathrm{~h}$ at ambient temperatures and for at least 3 months at $-20^{\circ} \mathrm{C}$.

\section{Application of the method}

To explore the applicability of the method, samples were obtained from two volunteer adult patients treated with vincristine after they had consented to the procedure.

A drop of blood was obtained with a finger prick made in the top of the finger with a disposable lancet. After puncture of the skin, the finger was gently massaged, and the drop of blood was collected on a filter card.

Figure 4 shows the concentration-time curves obtained in both patients by using the outlined procedure. Patient 1 was a 71-year-old man of $70 \mathrm{~kg}$, and patient 2 was a 69 year-old man of $96 \mathrm{~kg}$. Both patients were treated with $2 \mathrm{mg}$ vincristine as a bolus injection. The first sample was taken $5 \mathrm{~min}$ after the bolus injection. This example shows that the developed method is applicable to obtain pharmacokinetic data. Samples were obtained by an easy to use and non-invasive method.

\section{Conclusion}

In this paper, the development, validation and application of a LC-MS/MS method for the quantitative analysis of vincristine and actinomycin-D in human dried blood spots is described. A 0.25-in. disc was punched out from the dried blood spots. Vincristine and actinomycin-D were extracted from this punched-out disc by sonication during $15 \mathrm{~min}$ in a mixture of acetonitrile-methanol-water $(1: 1: 1$, $v / v / v)$ containing the internal standard vinorelbine. Chromatography was performed under alkaline conditions. A linear dynamic range from 1 to $100 \mathrm{ng} / \mathrm{mL}$ for vincristine and 2 to $250 \mathrm{ng} / \mathrm{mL}$ for actinomycin-D in blood was successfully validated. The method is easy to perform, accurate, precise, selective, reproducible and fast. The stability of the compounds for 3 months at $40-45^{\circ} \mathrm{C}$ indicates that collection of dried blood spots is feasible in resource-limited settings where refrigeration is not possible. Significant cost reductions can be obtained when filter cards are shipped instead of plasma samples on dry ice. We have demonstrated that dried blood spots, which can be sampled with a simple finger prick, can be used for pharmacokinetic studies of the anti-cancer agents vincristine and actinomycin-D and thus making the execution of the studies in the clinic much easier. However, one should realise that the use of dried blood spots results in a quantification in whole blood. Thus, results are different than in plasma, especially for drugs which are highly bound to blood components. The use of dried blood spots for the analysis of anti-cancer agents has not been described before. The described method opens up future opportunities for the analysis of other cancer agents in dried blood spots for the support of pharmacokinetic studies.

Open Access This article is distributed under the terms of the Creative Commons Attribution Noncommercial License which permits any noncommercial use, distribution, and reproduction in any medium, provided the original author(s) and source are credited.

\section{References}

1. Alfazil AA, Anderson RA (2008) J Anal Toxicol 32:511-515

2. Bergqvist Y, al Kabbani J, Krysen B, Berggren PI, Rombo L (1993) J Chromatogr 615:297-302

3. Blessborn D, Romsing S, Annerberg A, Sundquist D, Bjorkman A, Lindegardh N, Bergqvist Y (2007) J Pharm Biomed Anal 45:282-287

4. Kolawole JA, Mustapha A (2000) Biopharm Drug Dispos 21:345-352

5. Kolawole JA, Taylor RB, Moody RR (1995) J Chromatogr B Biomed Appl 674:149-154

6. Lejeune D, Souletie I, Houze S, Le bricon T, Le bras J, Gourmel B, Houze P (2007) J Pharm Biomed Anal 43:1106-1115

7. Minzi OM, Massele AY, Gustafsson LL, Ericsson O (2005) J Chromatogr B Analyt Technol Biomed Life Sci 814:179-183

8. Ntale M, Mahindi M, Ogwal-Okeng JW, Gustafsson LL, Beck O (2007) J Chromatogr B Analyt Technol Biomed Life Sci 859:137-140

9. Malm M, Lindegardh N, Bergqvist Y (2004) J Chromatogr B Analyt Technol Biomed Life Sci 809:43-49

10. la Marca G, Malvagia S, Filippi L, Fiorini P, Innocenti M, Luceri F, Pieraccini G, Moneti G, Francese S, Dani FR, Guerrini R (2008) J Pharm Biomed Anal 48:1392-1396

11. Coombes EJ, Gamlen TR, Batstone GF, Leigh PN (1984) Ann Clin Biochem 21(Pt 6):519-522

12. Cheung CY, van der Heijden J, Hoogtanders K, Christiaans M, Liu YL, Chan YH, Choi KS, van de Plas A, Shek CC, Chau KF, Li CS, van Hooff J, Stolk L (2008) Transpl Int 21:140-145

13. Hoogtanders K, van der Heijden J, Christiaans M, Edelbroek P, van Hooff JP, Stolk LM (2007) J Pharm Biomed Anal 44:658-664

14. Hoogtanders K, van der Heijden J, Christiaans M, van de Plas A, van Hooff J, Stolk L (2007) Transplantation 83:237-238

15. Webb NJ, Roberts D, Preziosi R, Keevil BG (2005) Pediatr Transplant 9:729-733

16. van der Heijden J, de Beer Y, Hoogtanders K, Christiaans M, de Jong GJ, Neef C, Stolk L (2009) J Pharm Biomed Anal. doi:10.1016/j.jpba.2008.11.021.

17. Allanson AL, Cotton MM, Tettey JN, Boyter AC (2007) J Pharm Biomed Anal 44:963-969

18. Fujimoto T, Tsuda Y, Tawa R, Hirose S (1989) Clin Chem 35:867-869

19. Tawa R, Hirose S, Fujimoto T (1989) J Chromatogr 490:125-132

20. Ronn AM, Lemnge MM, Angelo HR, Bygbjerg IC (1995) Ther Drug Monit 17:79-83

21. Barfield M, Spooner N, Lad R, Parry S, Fowles S (2008) J Chromatogr B Analyt Technol Biomed Life Sci 870:32-37

22. Boy RG, Henseler J, Mattern R, Skopp G (2008) Ther Drug Monit 30:733-739

23. Spooner N, Lad R, Barfield M (2009) Anal Chem 81:1557-1563 
24. Oliveira EJ, Watson DG, Morton NS (2002) J Pharm Biomed Anal 29:803-809

25. Hibberd SG, Alveyn C, Coombes EJ, Holgate ST (1986) Br J Clin Pharmacol 22:337-341

26. Koal T, Burhenne H, Romling R, Svoboda M, Resch K, Kaever V (2005) Rapid Commun Mass Spectrom 19:2995-3001

27. ter Heine R, Rosing H, van Gorp EC, Mulder JW, van der Steeg WA, Beijnen JH, Huitema AD (2008) J Chromatogr B Analyt Technol Biomed Life Sci 867:205-212

28. Damen CW, Israëls T, Caron HN, Schellens JH, Rosing H, Beijnen JH (2009) Rapid Commun Mass Spectrom 23:763774
29. Knudsen RC, Slazyk WE, Richmond JY, Hannon WH (1995) http://www.cdc.gov/od/ohs/biosfty/driblood.htm

30. Rosing H, Man W, Doyle E, Bult A, Beijnen JH (2000) J Liq Chromatogr Relat Technol 23:329-354

31. U.S.Food and Drug Administration: Centre for Drug Evaluation and Research (2001) Available at: www fda gov/cder/guidance/ $4252 \mathrm{fnl} \mathrm{htm}$

32. Viswanathan CT, Bansal S, Booth B, DeStefano AJ, Rose MJ, Sailstad J, Shah VP, Skelly JP, Swann PG, Weiner R (2007) Pharm Res 24:1962-1973

33. Polson C, Sarkar P, Incledon B, Raguvaran V, Grant R (2003) J Chromatogr B Analyt Technol Biomed Life Sci 785:263-275 